\title{
Different body mass index grade on the risk of developing glioma: a meta-analysis
}

\author{
Zi-Feng Dai, Qi-Lin Huang ${ }^{*}$ and Hai-Peng Liu
}

\begin{abstract}
Background: Previous studies reported conflicting results about the risk of developing glioma and different body mass index. So we decided to execute a meta-analysis to solve the dispute.

Methods: Comprehensive literature retrieval was carried in PubMed, MEDLINE, and EMBASE up to September 15, 2014. Hand literature information retrieval was not carried. Six studies were fit for this meta-analysis. Pooled hazard ratio (HR) and $95 \%$ confidence interval (Cl) of different body mass index grade were performed by fixed/random-effects models, except for normal weight which was referent.

Results: Data of 3726 cases were included. Compared with normal weight $\left(20 \mathrm{~kg} \cdot \mathrm{m}^{-2}<\right.$ body mass index $\left.(\mathrm{BMI}) \leq 24.9 \mathrm{~kg} \cdot \mathrm{m}^{-2}\right)$, the underweight $\left(\mathrm{BMI} \leq 20 \mathrm{~kg} \cdot \mathrm{m}^{-2}\right)$ might have lower incidence on the risk of developing glioma ( $\mathrm{HR}=1.08,95 \% \mathrm{Cl}$ ranged 0.74 to $1.58, P=0.678)$. While the overweight $\left(25 \mathrm{~kg} \cdot \mathrm{m}^{-2}<\mathrm{BMI} \leq 29.9 \mathrm{~kg} \cdot \mathrm{m}^{-2}\right.$ ) and obesity (BMI $\geq 30 \mathrm{~kg} \cdot \mathrm{m}^{-2}$ ) were performed as a risk factor of developing glioma. The pooled HR of overweight group was 1.12 (95\% Cl ranged 1.02 to $1.22, P=0.013)$; the pooled HR of obesity was $1.14(95 \% \mathrm{Cl}$ ranged 1.02 to $1.27, P=0.017)$. Sensitivity analysis approved that our results were stable. There was no publication bias of these studies.

Conclusions: Underweight could decrease the risk of developing glioma. Excess BMI was considered as a risk factor to develop glioma.
\end{abstract}

Keywords: Body mass index, Overweight, Obesity, Glioma, Meta-analysis

\section{Background}

According to the diagnostic criteria of Tumours of the Central Nervous System of 2007 version, gliomas are divided into grade I IV; grade III and IV tumors are considered malignant gliomas [1], which account for $30 \%$ primary CNS tumors [2]. Gliomas are considered as diffuse infiltration of white matter tracts [3]. Compared with common magnetic resonance (MR) sequences which is insensitivity for detecting the boundary of tumor [3, 4], MRS or/ and DTI is/are effective methods to distinguish the infiltration area of glioma [5]. There is a great progress in surgical techniques and chemo-radiotherapy, but the median survival time of patients is $12-15$ months [6]. The patients 5 -year survival rate of WHO grade III glioma is $18 \%$ and it is $<5 \%$ for WHO grade IV tumors [7].

\footnotetext{
* Correspondence: hqlxqyy@sina.com

Department of Neurosurgery, Xinqiao Hospital, The Third Military Medical University, Chongqing 400037, China
}

Body mass index (BMI $\left.\left(\mathrm{kg} . \mathrm{m}^{-2}\right)\right)$ was calculated as weight $(\mathrm{kg})$ divided by height $(\mathrm{cm})$ squared and categorized as underweight when $\mathrm{BMI} \leq 20 \mathrm{~kg} \cdot \mathrm{m}^{-2}$, normal weight when $20 \mathrm{~kg} \cdot \mathrm{m}^{-2}<\mathrm{BMI} \leq 24.9 \mathrm{~kg} \cdot \mathrm{m}^{-2}$, overweight when $25 \mathrm{~kg} \cdot \mathrm{m}^{-2}<\mathrm{BMI} \leq 29.9 \mathrm{~kg} \cdot \mathrm{m}^{-2}$ and obesity when BMI $\geq 30 \mathrm{~kg} \cdot \mathrm{m}^{-2}$ [8]. Previous studies have shown overweight and obese contributed to increase the fatalities of endometrial cancer, colon cancer, and renal carcinma [9]. But the relationships between developing glia and BMI are uncertain. Several recent studies orted excess BMI was a predictor of glioma risk 11, whereas other studies did not show the similar outcome $[8,12-14]$. For solving this controversy, a

\section{Patients and methods}

\section{Literature retrieval and inclusive criteria}

A literature search was executed in PubMed, MEDLINE, and EMBASE from inception to September 15, 2014. 
The search strategies used for each database were as follows: "body mass index", "overweight", "obesity" combined with "glioma" which was a MeSH and limited in "human". Two reviewers independently sorted out eligible trials according to the following inclusive criteria: (I) a clear diagnosis of glioma; (II) underweight, overweight, or obesity defined by BMI; (III) relative risk (RR) or hazard ratio (HR) with $95 \%$ confidence interval (CI) of BMI was reported; (IV) we included the most recent and informative paper, if more than one article was found on the same trial; $(\mathrm{V})$ we excluded those studies which were not fit for our inclusion criteria.

\section{Data extraction and literature quality evaluation}

Two reviewers (Z.F Dai and H.P Liu) independently sorted out eligible trials according to inclusive criteria. Data extraction was performed by two reviewers which included the first author, year of publication, study design, country of study, the number of male and female, median followup, median age, HR, and $95 \%$ CI (Table 1). Any disagreements were resolved by discussion.

We used the Newcastle-Ottawa scale (NOS) to evaluate the quality of papers. The NOS is an evaluation standard of nonrandomized controlled trials composed with three major parts: selection of the study groups (0-4 stars), comparability of cases and controls ( $0-2$ stars), or cohorts, and ascertainment of exposure/outcome (0-3 stars). A study was considered a high-quality research when its NOS were equal or greater than 6 stars [15].

\section{Statistical analysis}

The pooled HRs and $95 \%$ CIs were assessed to know the correlation risk between glioma and underweight, overweight, or obesity. Greenland reported "if the outcome under study is rare in all populations and subgroups under review, one can generally ignore the distinctions among the various measures of relative risk (e.g., odds ratios, rate ratios, and risk ratios)" [16]. So we used this principle in the study of Benson et al.: RRs were accurate approximations of HRs [10]. Statistical heterogeneity was quantified with $I^{2}$ statistic and Cochran's Q with a significant level at $P<0.1$ [17]. Fixed-effects model was executed for summary data, if heterogeneity was not significant $\left(I^{2}<50 \%\right)$. While if $I^{2}>50 \%$, the random-effects model was selected [17]. When $I^{2}$ was less than $25 \%$, the heterogeneity was low; When $I^{2}$ was ranged $25 \%$ from $50 \%$, the heterogeneity was moderate; and when $I^{2}$ was more than $50 \%$, the heterogeneity was high [18]. Sensitivity analysis was carried to evaluate the effect of each inclusive study on the results by excluding one study at a time. Sensitivity analysis was performed to evaluate the effect of each inclusive study on the results by excluding one study at a time. Begg's test was performed to examine publication bias at two-side test $P$ value $<0.05$. All analyses were performed in STATA 12.0 version. All analyses were conducted in STATA 12.0 version. Screening article was based on preferred reporting items for systematic reviews and meta-analyses (PRISMA) statement (Review Manager Version 5.2 (Revman, the Cochrane Collaboration, Oxford, England)) [19].

\section{Results}

\section{Characteristics of included trials and patients}

With our search strategy, 450 trials were satisfied, and Fig. 1 shows a flow diagram for the selection process. After reading the titles, 23 interesting articles were taken. After reading the abstracts, seven papers were needed to get full text. After reviewing the full-text, six trials met the inclusion criteria and were included in meta-analysis [8, 10-14]. Two studies were performed in the USA [11-13], and three trials in Europe $[8,10,14]$. Four studies

Table 1 Characteristics of the five trials included in meta-analysis

\begin{tabular}{|c|c|c|c|c|c|c|c|c|}
\hline Author & Year & Design & Country & Male & Female & $\begin{array}{l}\text { Median } \\
\text { follow-up } \\
\text { (months) }\end{array}$ & Median age (years) & NOS \\
\hline Benson [10] & 2008 & $\begin{array}{l}\text { Cohort } \\
\text { study }\end{array}$ & UK & / & 646 & 74.4 & $57 \pm 4.5$ & $* * * * * *$ \\
\hline Siegel [11] & 2013 & $\begin{array}{l}\text { Case- } \\
\text { control } \\
\text { study }\end{array}$ & USA & 506 & 347 & 12.4 & $57 \pm 13.3$ & $* * * * * *$ \\
\hline Wiedmann [8] & 2013 & $\begin{array}{l}\text { Cohort } \\
\text { study }\end{array}$ & Norway & 83 & 65 & 282 & $48.1(20-101)$ & $* * * * * *$ \\
\hline Michaud [14] & 2011 & $\begin{array}{l}\text { Cohort } \\
\text { study }\end{array}$ & Cross-country $^{\mathrm{a}}$ & 167 & 173 & 100.8 & / & $* * * * * * *$ \\
\hline Jones [13] & 2010 & $\begin{array}{l}\text { Cohort } \\
\text { study }\end{array}$ & USA & 832 & 427 & 40 & 58 & $* * * * * *$ \\
\hline Moore [12] & 2009 & $\begin{array}{l}\text { Cohort } \\
\text { study }\end{array}$ & USA & 341 & 139 & 98.4 & / & $* * * * * *$ \\
\hline
\end{tabular}




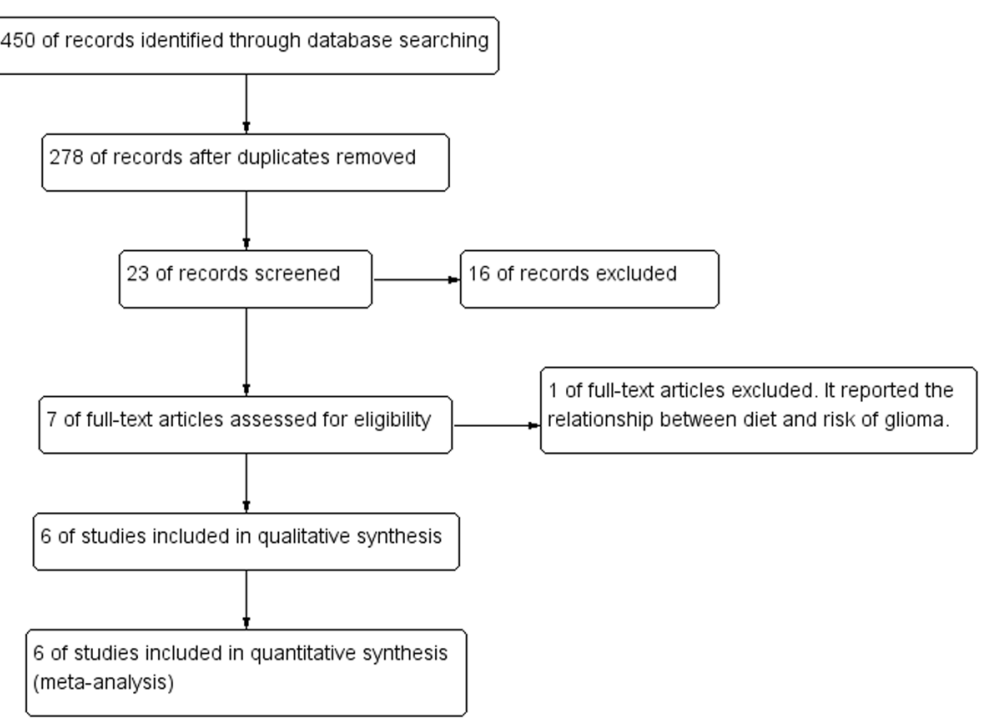

Fig. 1 The PRISMA statement of meta-analysis

included women and men $[8,11-14]$, and one study included women only [10]. All included studies were of high quality evaluated by NOS, which were equal to or more than six stars. Detailed characteristics and NOS score of the included studies are shown in Table 1.

\section{Meta-analysis}

Six studies $[8,10-14]$ which contained 3726 patients were included into meta-analysis. There was no significant heterogeneity between these studies $\left(I^{2}=0.0 \%, P=0.912\right)$, so the fixed-effects model of analysis was performed. The

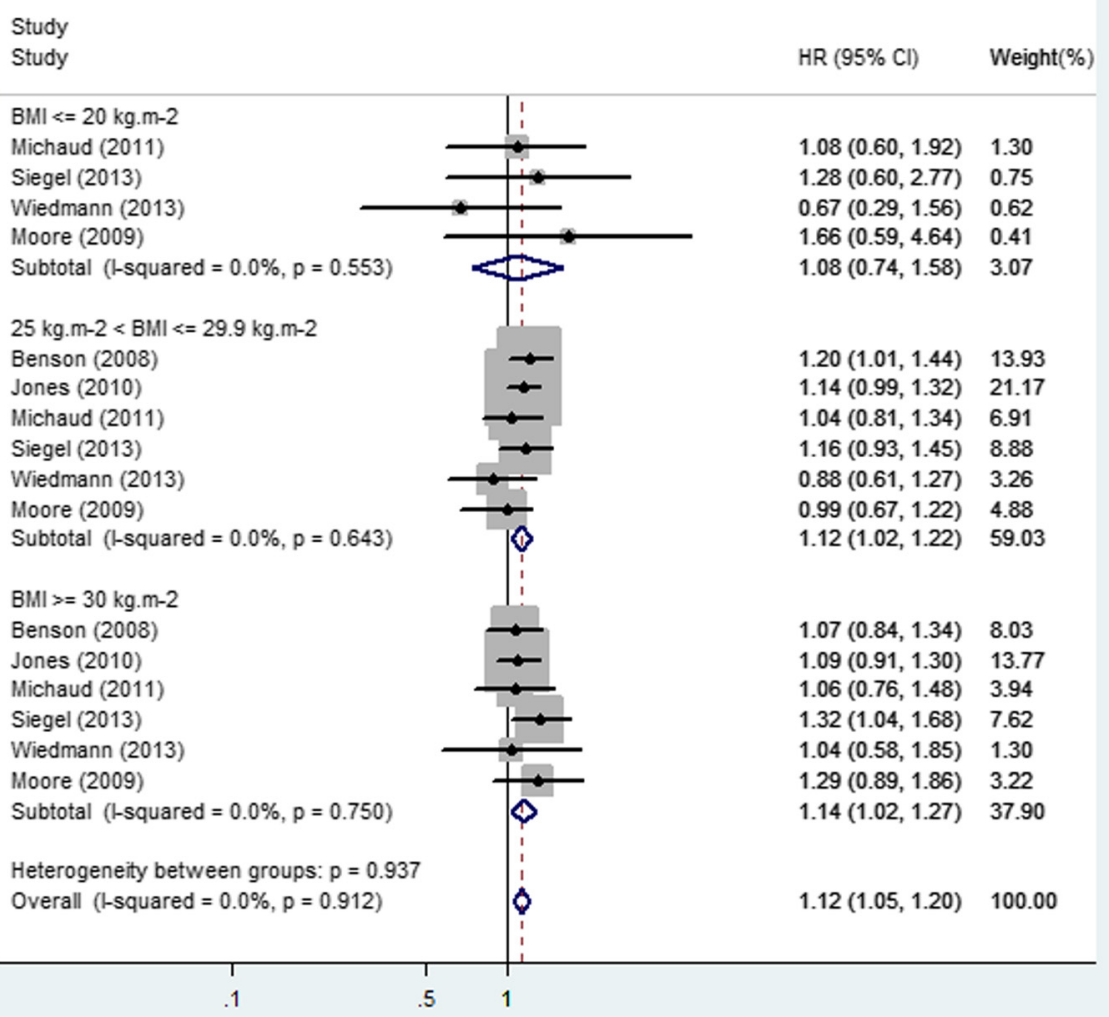

Fig. 2 Forest plots of meta-analysis results of underweight, overweight, and obesity, when normal weight was referent 


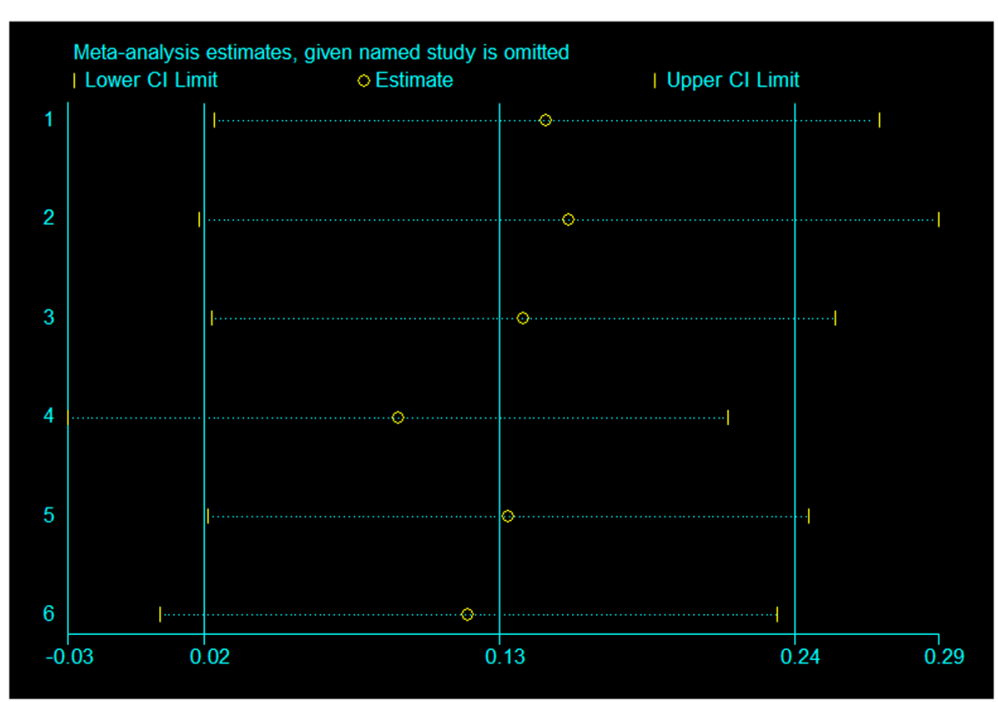

Fig. 3 Sensitivity analysis for obesity

pooled HR of all studies was 1.12 (95\% CI ranged 1.05 to $1.20, P=0.001$ ) (Fig. 2), which mean excess BMI was a risk factor to develop glioma.

Three studies $[8,11,12,14]$ provided the HR of underweight. The heterogeneity was significant in these studies $\left(I^{2}=0.0 \%, P=0.553\right)$, so random-effects analysis was performed. The pooled HR of all studies was 1.08 (95\% CI ranged 0.74 to $1.58, P=0.678$ ) (Fig. 3), which mean underweight might decrease the risk of suffering from glioma.

Six studies $[8,10-14]$ provided the HR of overweight and obesity. There was no significant heterogeneity in two groups (all $I^{2}=0.0 \%$ ), so fixed-effects analysis was performed. The pooled HR of overweight group was 1.12 (95\% CI ranged 1.02 to $1.22, P=0.013$ ); the pooled
HR of obesity was 1.14 (95\% CI ranged 1.02 to 1.27 , $P=0.017$ ) (Fig. 2). Excess BMI was considered as a risk factor of developing glioma.

\section{Sensitive analysis}

Sensitivity analysis was carried by excluding one study at a time. There did not exist any one article that could significantly influence the overall result stability individually (Fig. 3).

\section{Publication bias}

The outcomes of Egger's test $(t=0.17, P=0.873)$ and symmetric funnel plot showed that there was no publication bias from these outcomes (Fig. 4).

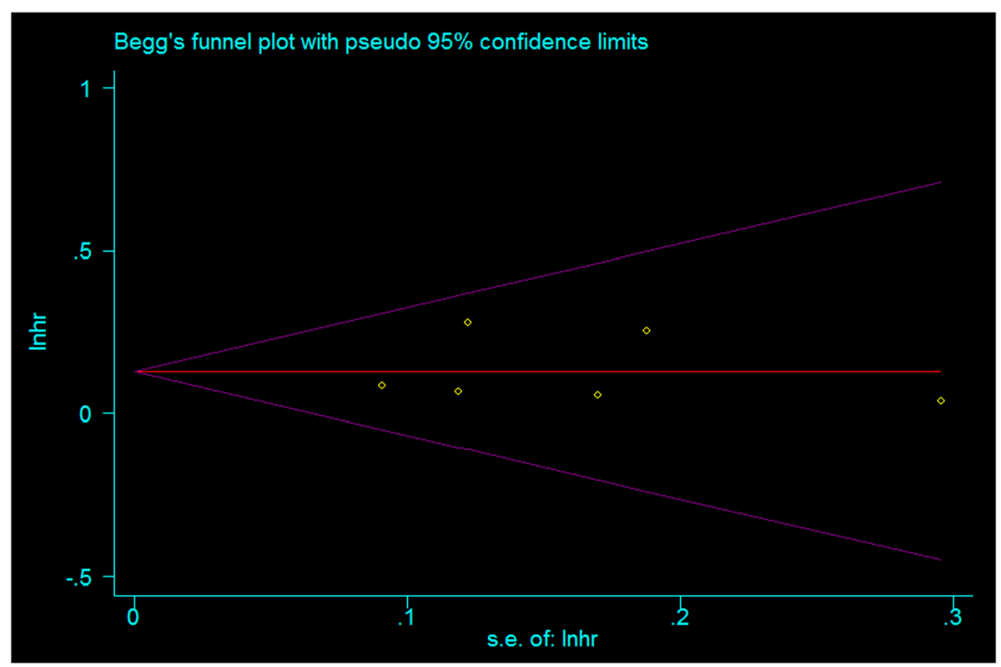

Fig. 4 Funnel plot for publication bias of obesity 


\section{Discussion}

The meta-analysis showed the relationship of glioma with underweight, overweight, and obesity compared normal weight. Only three studies to date have analyzed the relationship between the risk of glioma and underweight, and pooled HR of three studies show underweight could decrease the risk of developing glioma $[8,11,14]$. Excess BMI (BMI $\left.\geq 25 \mathrm{~kg} \cdot \mathrm{m}^{-2}\right)$ was significantly associated with a danger of developing glioma. Many studies reported the overweight and obesity were independent risk factors for poor outcome in patients with glioma $[8,11-14]$. At present, several potential theories have been built to explain how obesity can influence the development of glioma. The most well-known mechanism is the insulin-like growth factor (IGF) hypothesis of obesity-related cancer, which has been implicated in glioma proliferation and progression in vitro [20-25]. A 22-case-control study showed a positive correlation between serum IGF-1 levels and glioma risk [26]. IGF-1 inhibitor was found effectively to suppress growth of glioblastoma cell and induced tumor regression in vitro [27]. There is a peak level of IGF during fetal brain development, and it decreases with age. But it reappears in nervous tissue of glioma cells [28]. Insulin resistance and hyperinsulinemia are very common among excess body mass especially obesity [29], which increase the level of free IGF. The free IGF can bind insulin-like growth factor binding protein 1 (IGFBP-1) and insulin-like growth factor binding protein 2 (IGFBP2). Correspondence with a decrease of the binding protein, more and more higher circulating concentrations of free or bioactive insulin-like growth factor 1 (IGF-1), was detected $[21,30]$.

Basing on our findings, we thought weight loss is beneficial which may reduce insulin resistance in obese patients. In addition, nutrients and phytochemicals in fruit and vegetables might decrease glioma risk [31], while socioeconomic level, daily alcohol intake, smoking status, number of full-term pregnancies, age at first birth, and oral contraceptive use were not significantly associated with the incidence of glioma [10]. Moore et al. found no link between weight gain between ages 18 and 50 years and glioma risk [12].

As we know, this is the first meta-analysis illustrating the correlation of different BMI grades on the risk of glioma. There are some advantages of this meta-analysis. Firstly, meta-analysis can assess the consistency of result and find the origin of heterogeneity. Secondly, metaanalysis can evaluate and summarize results from different studies which can increase the statistical efficiency and accuracy. Thirdly, we could do detailed subgroup analysis to identify risk factors relative to glioma.

Several potential limitations of this meta-analysis should be noted. First, the number of included studies was small which might let us underestimate the true association. Second, as all included studies were observational, we cannot exclude all confounders like age, region, and race. Third, because of our strict inclusive criteria, many articles might exclude subject. Forth, the data were not stratified according to the WHO grade of tumors. Finally, unpublished negative results were needed to be considered.

\section{Conclusion}

Underweight could decrease the risk of developing glioma. Excess BMI was considered as a risk factor for developing glioma. But this outcome needs more prospective studies to further confirm the study.

\section{Competing interests}

The authors declare that they have no competing interests.

\section{Authors' contributions}

$\mathrm{ZD}$ and $\mathrm{QH}$ designed the research strategy; $\mathrm{ZD}$ and $\mathrm{HL}$ extracted and analyzed data; ZD wrote the main manuscript text. QH helped to correct the manuscript. All authors read and approved the final manuscript.

\section{Acknowledgements}

Doctor wei Zhang helped in formulating the research strategy, gaining data, and data analysis. Shenqing LV modified this paper. We also greatly appreciate all healthcare workers of the neurosurgery department in Xinqiao hospital. Thanks for the support.

Received: 6 April 2015 Accepted: 6 July 2015

Published online: 18 October 2015

\section{References}

1. Louis DNOH, Wiestler OD, Cavenee WK, Burger PC, Jouvet A, Scheithauer BW, et al. The 2007 WHO Classification of Tumours of the Central Nervous System. Acta Neuropathol. 2007;114:97-109.

2. Ronning PA, Helseth E, Meling TR, Johannesen TB. A population-based study on the effect of temozolomide in the treatment of glioblastoma multiforme. Neuro-oncology. 2012;14(9):1178-84.

3. Wang W, Steward CE, Desmond PM. Diffusion tensor imaging in glioblastoma multiforme and brain metastases: the role of $p, q, L$, and fractional anisotropy. AJNR Am J Neuroradiol. 2009;30(1):203-8.

4. Goebell EFJ, Ding XQ, Paustenbach S, Nietz S, Heese O. Disarrangement of fiber tracts and decline of neuronal density correlate in glioma patients - a combined diffusion tensor imaging and $1 \mathrm{H}-\mathrm{MR}$ spectroscopy study. AJNR Am J Neuroradiol. 2006;27:1426-31.

5. Zou QG, Xu HB, Liu F, Guo W, Kong XC, Wu Y. In the assessment of supratentorial glioma grade: the combined role of multivoxel proton MR spectroscopy and diffusion tensor imaging. Clin Radiol. 2011;66(10):953-60.

6. Stupp R, Hegi ME, Gilbert MR, Chakravarti A. Chemoradiotherapy in malignant glioma: standard of care and future directions. J Clin Oncol. 2007;25(26):4127-36.

7. Tait MJPV, Loosemore A, Bell BA, Papadopoulos MC. Survival of patients with glioblastoma multiform has not improved between 1993 and 2004: analysis of 625 cases. Br J Neurosurg. 2007;21:496-500.

8. Wiedmann M, Brunborg C, Lindemann K, Johannesen TB, Vatten L, Helseth $E$, et al. Body mass index and the risk of meningioma, glioma and schwannoma in a large prospective cohort study (The HUNT Study). Br J Cancer. 2013;109(1):289-94

9. Renehan AG, Roberts DL, Dive C. Obesity and cancer: pathophysiological and biological mechanisms. Arch Physiol Biochem. 2008;114(1):71-83.

10. Benson VS, Pirie K, Green J, Casabonne D, Beral V, Million Women Study C. Lifestyle factors and primary glioma and meningioma tumours in the Million Women Study cohort. Br J Cancer. 2008;99(1):185-90.

11. Siegel EM, Nabors LB, Thompson RC, Olson JJ, Browning JE, Madden MH, et al. Prediagnostic body weight and survival in high grade glioma. J Neurooncol. 2013;114(1):79-84. 
12. Moore SC, Rajaraman P, Dubrow R, Darefsky AS, Koebnick C, Hollenbeck A, et al. Height, body mass index, and physical activity in relation to glioma risk. Cancer Res. 2009;69(21):8349-55.

13. Jones LW, Ali-Osman F, Lipp E, Marcello JE, McCarthy B, McCoy L, et al. Association between body mass index and mortality in patients with glioblastoma mutliforme. Cancer Cause Control. 2010;21(12):2195-201.

14. Michaud DS, Bove G, Gallo V, Schlehofer B, Tjonneland A, Olsen A, et al. Anthropometric measures, physical activity, and risk of glioma and meningioma in a large prospective cohort study. Canc Prev Res. 2011:4(9):1385-92.

15. Wells GASB, O'Connell D, Peterson J, Welch V. The Newcastle-Ottawa Scale (NOS) for assessing the quality of nonrandomized studies in meta-analyses. 2013.

16. Greenland S. Quantitative methods in the review of epidemiologic literature. Epidemiol Rev. 1987;9:1-30.

17. Higgins JP, Thompson SG. Quantifying heterogeneity in a meta-analysis. Stat Med. 2002;21(11):1539-58.

18. Guyatt GH, Oxman AD, Kunz R, Woodcock J, Brozek J, Helfand M, et al. GRADE guidelines: 7. Rating the quality of evidence-inconsistency. J Clin Epidemiol. 2011;64(12):1294-302.

19. Moher DLA, Tetzlaff J. Preferred reporting items for systematic reviews and meta-analyses. the PRISMA statement. BMJ. 2009;339:b2535.

20. Belfiore A, Frasca F, Pandini G, Sciacca L, Vigneri R. Insulin receptor isoforms and insulin receptor/insulin-like growth factor receptor hybrids in physiology and disease. Endocr Rev. 2009;30(6):586-623.

21. Trojan J, Cloix JF, Ardourel MY, Chatel M, Anthony DD. Insulin-like growth factor type I biology and targeting in malignant gliomas. Neuroscience. 2007;145(3):795-811.

22. Wang HWH, Shen W. Insulin-like growth factor-binding protein 2 enhances GBM invasion by activating invasion-enhancing genes. Cancer Res. 2003;63:4315-21.

23. Renehan AG, Frystyk J, Flyvbjerg A. Obesity and cancer risk: the role of the insulin-IGF axis. Trends Endocrinol Metab. 2006;17(8):328-36.

24. Basen-Engquist $\mathrm{K}$, Chang M. Obesity and cancer risk: recent review and evidence. Curr Oncol Rep. 2011;13(1):71-6.

25. McDonald KL, O'Sullivan MG, Parkinson JF, Shaw JM, Payne CA, Brewer JM, et al. IQGAP1 and IGFBP2: valuable biomarkers for determining prognosis in glioma patients. J Neuropathol Exp Neurol. 2007;66(5):405-17.

26. Lonn S, Inskip PD, Pollak MN, Weinstein SJ, Virtamo J, Albanes D. Glioma risk in relation to serum levels of insulin-like growth factors. Cancer Epidemiol Biomarkers Prev. 2007;16(4):844-6.

27. Yin SGA, Stromberg T, Khan Z, Andersson S, Zheng H, Ericsson C, et al. Targeting the insulin-like growth factor-1 receptor by picropodophyllin as a treatment option for glioblastoma. Neuro Oncol. 2010;2010:19-27.

28. Kiess WLL, Graham DE, Greenstein L, Tseng LY, Rechler MM, Nissley SP. Rat C6 glial cells synthesize insulin-like growth factor I (IGF-I) and express IGF-I receptors and IGF-II/mannose 6-phosphate receptors. Endocrinology. 2010;124:1727-36.

29. Ish-Shalom D, Christoffersen CT, Vorwerk P, Sacerdoti-Sierra N, Shymko RM, Naor D, et al. Mitogenic properties of insulin and insulin analogues mediated by the insulin receptor. Diabetologia. 1997;40 Suppl 2:S25-31.

30. Ercole JAYP. Expanding the mind. Insulin-like growth factor I and brain development. Endocrinology. 2008;149:5958-62.

31. Wrensch M, Minn Y, Chew T, Bondy M, Berger MS. Epidemiology of primary brain tumors: current concepts and review of the literature. Neuro-oncology. 2002;4(4):278-99.

\section{Submit your next manuscript to BioMed Central and take full advantage of:}

- Convenient online submission

- Thorough peer review

- No space constraints or color figure charges

- Immediate publication on acceptance

- Inclusion in PubMed, CAS, Scopus and Google Scholar

- Research which is freely available for redistribution 